\title{
Examining the century dynamic change of forest oxygen production in Heilongjiang Province, China
}

\author{
L. J. Zhang' ${ }^{1}$ W. L. Li ${ }^{2}$ C. Y. Jiang ${ }^{1} \cdot$ S. Y. Zang ${ }^{1}$
}

Received: 11 September 2013/Revised: 28 October 2013/Accepted: 15 March 2015/Published online: 9 April 2015

(C) Islamic Azad University (IAU) 2015

\begin{abstract}
During the past century, Heilongjiang Province, the highest forest coverage province of China, has experienced rapid deforestation, with coverage decreasing by an estimated $40 \%$. As the important role that forest vegetation plays in oxygen production and environmental optimization, dynamic change analysis of forest and forest oxygen production has become more and more important. In this study, we examined changes in forest and forest oxygen production, as well as the impact of natural and human activities on such change in Heilongjiang Province, China. In particular, the net ecosystem productivity (NEP) of the forest was generated by the C-FIX model, and the relationship between NEP and forest oxygen production was examined. Analysis results indicate that in the past century, the forest area and oxygen production of Heilongjiang Province has been reduced by about $106,667.57 \mathrm{~km}^{2}(37.16 \%)$ and 56.22 million tons (33\%), respectively. Moreover, the spatial analysis results suggest significant spatial variation of forest oxygen production in Heilongjiang Province, China. Specifically, oxygen production in the southwest has shifted from the highest area to the lowest area, and significant decreases in forest oxygen production have been observed in the Sanjiang Plain and the central part of Heilongjiang Province. In
\end{abstract}

S. Y. Zang

zsy6311@163.com

1 Key Laboratory of Remote Sensing Monitoring of Geographic Environment, College of Heilongjiang Province, Harbin Normal University, No.1 South Shida Road, Limin Economic Development Zone, Harbin 150025, Heilongjiang, People's Republic of China

2 Department of Geography, University of WisconsinMilwaukee, 3210 N Maryland Ave, Milwaukee, WI 53211, USA addition, oxygen production also presents decreasing tendencies $(>90 \%)$ in Daqing City and Qiqihar. The analysis of the impact of climate change and human activities on forest oxygen production indicates that human activities have the largest impact on forest oxygen production, accounting for about $67.95 \%$ of the decrease.

Keywords Forest oxygen production - Forest cover change $\cdot$ Century dynamic change $\cdot$ Heilongjiang

\section{Introduction}

With further research on air quality, concerns have been raised on the changes of oxygen content in the atmosphere. More and more studies have demonstrated that the earth's atmospheric oxygen content peaked in the planet's early days, with an average prehistoric content of atmospheric oxygen of between 30 and $35 \%$; however, it is only $21 \%$ now and $15 \%$ or even less in the cities or industrial parks with high pollution rates (Bekker et al. 2004; Kasting et al. 1979; Kump and Mark 2007; Chuai et al. 2012). Scholars also found that the oxygen content of the lower atmosphere is decreasing at an average rate of $2 \mathrm{ppm}$ per year (Manning et al. 2003; $\mathrm{Li}$ and $\mathrm{Wu}$ 2013; $\mathrm{Li}$ et al. 2012), and atmospheric oxygen content decreases both annually and seasonally (Keeling and Stephen 1992). The decreasing atmospheric oxygen content influences several issues associated with human health and environmental degradation. For example, when the atmospheric oxygen content is below $18 \%$, people can experience anoxia and chronic pain and diseases caused by cell hypoxia (Jacobsen 2008; Zhou 1999). In addition, the decrease in oxygen and increases in other atmosphere components, such as carbon dioxide $\left(\mathrm{CO}_{2}\right)$, can exert a significant negative effect on the 
surrounding environment. Therefore, the analysis of the dynamic change of oxygen production and assessment of the impacts of natural forces and human activities on such change has become more and more important.

Numerous methods have been developed and applied to estimate oxygen production. One general approach was implemented by calculating the oxygen level in fossil bubbles. Specifically, oxygen content was estimated through a biochemical model (Manning et al. 2003; Keeling and Stephen 1992; Keeling et al. 1998; Abbaspour et al. 2012) based on fossil carbon storage, atmospheric methane content, and soil iron metal content (Claire et al. 2006; Goldblatt et al. 2006; Bangian et al. 2012). Moreover, there were many reports that from the perspective of oxygen sources based on the photosynthesis principle (Sreenivas and Murakami 2005), regional oxygen production could be estimated by the carbon-oxygen balance method (Johnson and Francis 1970a, 1970b; Bortkovskii et al. 2007). According to the carbon-oxygen balance method, two approaches can be employed for calculating regional oxygen production. The first involves converting the consumption of the estimated regional oxygen (Ma et al. 2011), and the second estimates organic carbon produced by regional plants (Chen and Shan 2009; Zhang et al. 2007; Guang et al. 1998). In comparison, the first approach was much more subjective, and the second approach was applied more frequently and widely. In addition to the two carbonoxygen balance-based approaches, some scholars attempted to estimate oxygen production from vegetation gross primary production (GPP) (Chen and Shan 2009; Zhang et al. 2007) or net primary production (NPP) (Ma et al. 2011; Guang et al. 1998). The former method used the initial organic carbon produced by plants through photosynthesis; the latter one considered the residual organic carbon after plant respiration. Due to different theoretical basis, there was a significant difference between the estimated results. Based on the mechanisms of photosynthesis and respiration and the comparison of GPP and NPP, the consumption of organic carbon caused by plant respiration and incorporation was fully considered in net ecosystem productivity (NEP), which was net photosynthetic production (Lu 2003). Few relevant reports have determined net oxygen production estimated by NEP, and the existing studies rarely combine remote sensing and geographic information system (GIS) technology to analyze the spatial distribution and variation characteristics of regional oxygen production.

The decrease in the number of green plants areas can result in decreased oxygen production. Therefore, changes in atmospheric oxygen content can be indirectly revealed by simulating changes in oxygen sources. Forested land is an important part of terrestrial green vegetation and a significant ecological system for carbon fixation and oxygen release. Heilongjiang Province has the richest forest resources in China, accounting for 1/7 of the country's total forested area. The vast forest is an important source of oxygen and a reservoir of $\mathrm{CO}_{2}$, both of which play an important role in regulating the regional eco-environment. Due to the impact of human activities, the forested area in Heilongjiang has decreased by about $40 \%$ in the past 100 years, which can decrease forest oxygen production. However, in terms of natural influences, the released quantity of forest oxygen will theoretically increase due to climate warming and increasing $\mathrm{CO}_{2}$ concentration. No study has assessed the synergistic effects of these two opposing processes on forest oxygen production in Heilongjiang in the last century.

According to the forest cover information of Heilongjiang collected in 1900 and 2009, we simulated forest NEP using the C-FIX model. Based on the carbon-oxygen balance principle, forest oxygen quantities of Heilongjiang in the early and late twentieth century were simulated and analyzed with the GIS spatial analysis method to investigate the influence of changing forest properties and climate on the forest oxygen production.

\section{Materials and methods}

\section{Study area}

The Heilongjiang Province in northeastern China (see Fig. 1), covering an area of $460,000 \mathrm{~km}^{2}$ at $121^{\circ} 11^{\prime}-$ $135^{\circ} 05^{\prime} \mathrm{E}$ longitude $43^{\circ} 26^{\prime}-53^{\circ} 33^{\prime} \mathrm{N}$ latitude, was selected as the study area for this research. Heilongjiang Province is

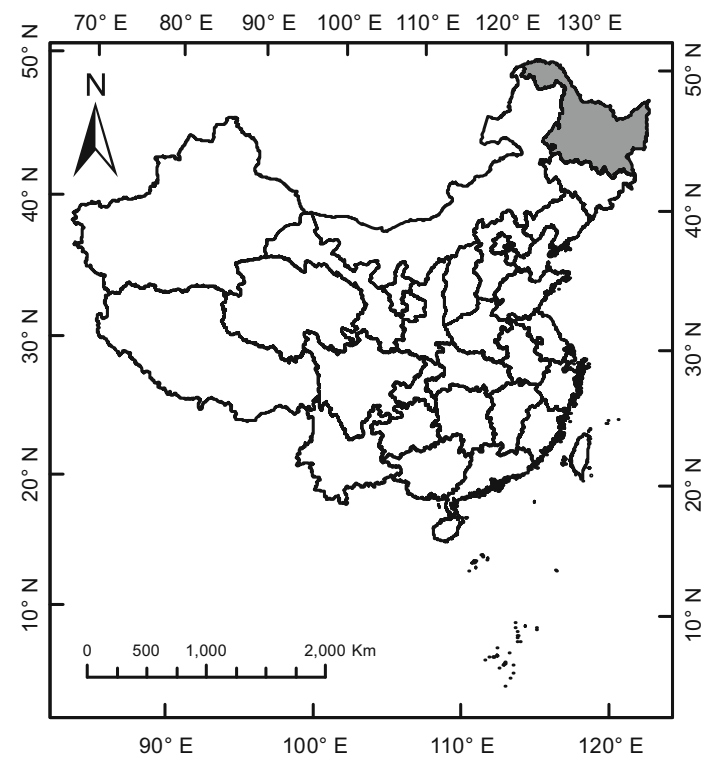

Fig. 1 Location of the study area 
the most forested province in China, and approximately $36.7 \%$ of its land is covered with forests, accounting for $1 / 7$ of the forested area in China. Heilongjiang is one of three famous black soil belts in the world (Zhang 2009). Natural temperate and boreal forests dominate the lands in this province and are distributed in the Greater Khingan Mountains, the Lesser Khingan Mountains, the Changbai Mountains, and the Wanda Mountains. Natural forests in this region have suffered as a result of long-term logging and unreasonable management. The climate in Heilongjiang Province is a typical temperate-boreal continental monsoon, with an annual average temperature of -4 to $5{ }^{\circ} \mathrm{C}$ and annual total precipitation of around 400-650 $\mathrm{mm}$. The temperature decreases from southeast to northwest, with the largest difference up to $10{ }^{\circ} \mathrm{C}$. The Heilongjiang Province has abundant resources of solar radiation about $46 \times 10^{8}-50 \times 10^{8} \mathrm{~J} / \mathrm{m}^{2}$. The total sunshine duration in the province is $2300-2800 \mathrm{~h}$, of which $44-48 \%$ is during the growing season.

\section{Materials}

\section{Forest cover information}

Forest cover information was assessed for Heilongjiang in 1900 and 1986. Firstly, a paper map (Li 1993) illustrating the forest distribution of Heilongjiang in 1900 and 1986 was scanned and registered with a geographic coordinates system map for vectorization (see Fig. 2a, b). Then, the normalized difference vegetation index (NDVI) of the forest in 1900 was calculated using a 1986 forest cover map. Forest cover information was also assessed for Heilongjiang in 2009. Based on Landsat ETM + remote sensing images collected from the Institute of Remote
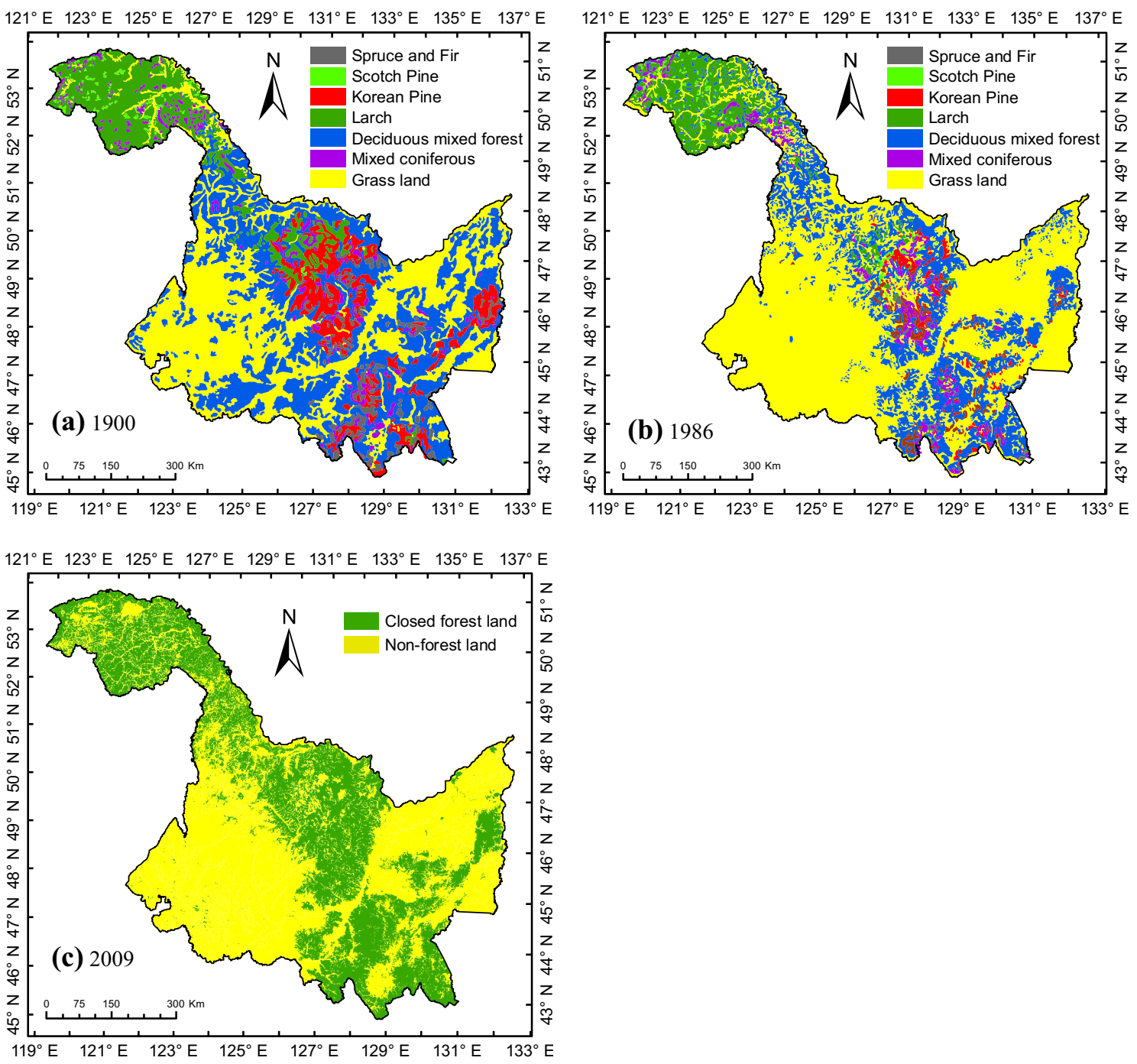

Fig. 2 Forest covers of Heilongjiang in 1900, 1986, and 2009 
Table 1 NDVI of vegetation cover form March to November between the $48^{\circ} \mathrm{N}$ and $49^{\circ} \mathrm{N}$

\begin{tabular}{llllllllll}
\hline Month & Mar & Apr & May & Jun & Jul & Aug & Sep & Oct & Nov \\
\hline Korean Pine & 0.2912 & 0.3482 & 0.6096 & 0.8571 & 0.8328 & 0.7749 & 0.7090 & 0.4707 & 0.3321 \\
Larch & 0.1928 & 0.2681 & 0.5413 & 0.8523 & 0.8350 & 0.7745 & 0.6786 & 0.3715 & 0.2269 \\
Spruce and Fir & 0.2527 & 0.3365 & 0.6008 & 0.8526 & 0.8447 & 0.7649 & 0.6993 & 0.4452 & 0.3111 \\
Scotch Pine & 0.2598 & 0.3229 & 0.5840 & 0.8461 & 0.8187 & 0.7596 & 0.6921 & 0.4434 & 0.2915 \\
Mixed coniferous forest & 0.2818 & 0.3388 & 0.5956 & 0.8548 & 0.8292 & 0.7733 & 0.7038 & 0.4530 & 0.3108 \\
Deciduous mixed forest & 0.1725 & 0.2601 & 0.5318 & 0.8308 & 0.8282 & 0.7672 & 0.6711 & 0.3713 & 0.2214 \\
\hline
\end{tabular}

Sensing, Chinese Academy of Sciences, the land-use patterns were divided into six types by supervised classification, including cultivated land, forestland, grassland, water area, construction land, and unused land. The forest cover information of forestland is shown in Fig. 2c.

\section{Acquisition of temperature and radiation information}

To ensure that the simulation results were comparable and reduce the impact of anomalies over the years, temperature and radiation data from 1900 and 2009 were replaced with average temperature and radiation values for 1900-1905 and 2005-2009, respectively. The average monthly temperatures were also calculated. The $0.5^{\circ} \times 0.5^{\circ}$ monthly grid temperature data were obtained from the Institute of Climate Research Unit (CRU), University of East Anglia. The climatic elements data from the CRU were calculated by interpolating the actual land surface observation data into the $0.5^{\circ} \times 0.5^{\circ}$ latitude and longitude grid data. Fortunately, the CRU data were found to be in accordance with the sequence of the actual observation data, passing significance tests in the regional scale of China (Fang et al. 2010; Zhang et al. 2004). The grid data, including Heilongjiang and nearby areas (comprising a total of 256 points), were extracted, and the Kriging interpolation method was used to construct a $1 \mathrm{~km} \times 1 \mathrm{~km}$ temperature grid map of Heilongjiang, covering dates from March to November in both 1900 and 2009. The monthly radiation flux data were subsequently considered. As the CRU data only included cloud cover data and not surface radiation data, the flux of solar radiation reaching the surface of the earth was calculated using astronomic radiation and cloud cover data (Huang and Pan 2008). The daily amount of astronomic radiation was calculated using a previously published formula (Zhou 2003).

A total of 256 points of grid data were extracted covering Heilongjiang and nearby areas during both 1900-1905 and 2005-2009. Solar radiation flux on the ground was subsequently calculated. The $1 \mathrm{~km} \times 1 \mathrm{~km}$ grid maps of ground radiation flux were then obtained through the Kriging interpolation method, covering dates from March to November during 1900-1905 and 2005-2009.

Acquisition of NDVI information in Heilongjiang Province

According to previous research, there have not been any obvious changes in NDVI for the vast zonal vegetation types found in northeast China, and there have been no large variations in the inter-annual change of NDVI for forest vegetation types (Chen et al. 2002, 2005; Li et al. 2013; Melemez 2013). We randomly selected larch, Korean pine, and deciduous forest as representatives to extract ten samples for averaging based on the NDVI data in August 1982-2009. The results indicated that there was not too much change for forest NDVI; the coefficients of variations were $0.00278,0.00208$, and 0.0028 for larch, Korean pine, and deciduous forest, respectively. Based on the above findings, anomalous fluctuations of NDVI over the years were disregarded, and the forest distribution map of Heilongjiang in 1986 and the NDVI information from 1984 to 1988 were super-positioned to obtain the monthly NDVI. Therefore, the monthly NDVI of every forest species for each latitude was extracted (take $48-49^{\circ} \mathrm{N}$ as an example, see Table 1). According to the latitude and forest type, the NDVI was assigned to the relevant forest type of 1900 , and the $1 \mathrm{~km} \times 1 \mathrm{~km}$ grid map of forest NDVI was obtained for Heilongjiang in 1900 from March to November. The NDVI for 2009 and the 1984-1988 period were downloaded from the United States National Aeronautics and Space Administration (NASA) Web site for the periods between March and September. This information was then superimposed onto the forest cover maps of Heilongjiang in 1986 and 2009 to extract the NDVI distribution map.

\section{Methods}

\section{Simulation of forest NEP using the C-FIX model}

The C-FIX model is a model of efficiency for solar energy utilization and is capable of achieving an estimation of 
NEP on a regional scale. The advantages of the model include a low requirement for input parameters, high computational efficiency, and high spatial-temporal resolution of output (Lu 2003). The C-FIX model can also efficiently simulate the daily NEP value $\left(\mathrm{gC} / \mathrm{m}^{2} /\right.$ day $)$ of each grid. The input parameters of the model are numbered at 15 , including the efficiencies for solar energy utilization, the gas constant, and meteorological elements, among others. The input parameters that need to be achieved include the daily average temperature, daily radiation flux, and NDVI, while the rest are constants or empirical values. Previous research has demonstrated that the C-FIX model can simulate vegetation productivity at all levels of Heilongjiang (Zhang 2009).

\section{Estimation of oxygen production by NEP}

During photosynthesis, $\mathrm{CO}_{2}$ and water $\left(\mathrm{H}_{2} \mathrm{O}\right)$ in the atmosphere under sunlight are absorbed by chlorophyll in plants and transformed into organic matter $\left(\mathrm{C}_{6} \mathrm{H}_{12} \mathrm{O}_{6}\right)$ and oxygen. At the same time, organic carbons and oxygen are consumed by plant respiration. The amount of residual organics after respiration is known as the NEP $\left(\mathrm{gC}^{2} \mathrm{~m}^{2} / \mathrm{a}\right)$. The amount of oxygen that corresponds to the NEP is the net amount of plant-produced oxygen. The mass ratio of output $\mathrm{C}$ simulated by the C-FIX model and oxygen has been established as 1:2.667.

\section{Spatial analysis method}

The ArcGIS spatial overlay, spatial statistics, and various other methods were employed to calculate the total forest oxygen production in each month and year in Heilongjiang Province and its subdivided cities and counties.

\section{Results and discussion}

\section{Changes in Forestry Area between 1900 and 2009}

The forestry area in Heilongjiang was $287,024.575 \mathrm{~km}^{2}$ in 1900 , and it decreased to $180,357.005 \mathrm{~km}^{2}$ in 2009 . This was an overall reduction of $106,667.570 \mathrm{~km}^{2}$ or $37.16 \%$ compared with 1900 (Table 2). Among the overall reduction, Heihe City had the largest decrease, with a $19,609.354 \mathrm{~km}^{2}$ loss, while Qitaihe had the smallest decrease at about $1583.426 \mathrm{~km}^{2}$. In terms of the percentage decrement rate, Suihua City, Jiamusi City, Jixi City, Qiqihar City, and Daqing City were reduced by more than $50 \%$. However, Daqing City lost the largest ratio at $94.67 \%$. In general, the southwest had the largest reductions, followed by the east, central, and north areas (see Fig. 3).

\section{Changes in the forest oxygen production between 1900 and 2009}

To avoid anomalous influences from atypical years, daily average temperatures, radiation, and $\mathrm{CO}_{2}$ concentration (Yan 2009) were replaced by daily average values from the periods of 1900-1905 and 2006-2009 to simulate NEP. These values were then converted into oxygen production. The simulated values of monthly and annual oxygen production in both 1900 and 2009 are shown in Table 3. The spatial distributions of annual oxygen production are shown in Fig. 4. The annual forest oxygen levels produced in 1900 and 2009 in Heilongjiang were 209.719 million tons and 153.503 million tons, respectively. In 2009, forest oxygen production was reduced by $26.81 \%$ (56.216 million tons less than the amount produced in 1900). Oxygen

Table 2 Forest area changes of Heilongjiang from 1900 to $2009\left(\mathrm{~km}^{2}\right)$

\begin{tabular}{lrrrr}
\hline District & \multicolumn{1}{c}{1900} & \multicolumn{1}{c}{2009} & Reduction in forest area & Percentage of reduction in forest area \\
\hline Greater Khingan Mountains & $56,729.425$ & $44,655.934$ & $-12,073.491$ & -21.28 \\
Yichun & $30,257.183$ & $24,930.616$ & -5326.567 & -17.60 \\
Mudanjiang & $33,394.696$ & $26,768.776$ & -6625.920 & -19.84 \\
Hegang & 7554.764 & 4922.680 & -2632.084 & -34.84 \\
Harbin & $32,686.656$ & $22,529.469$ & $-10,157.187$ & -31.07 \\
Heihe & $49,803.650$ & $30,194.296$ & $-19,609.354$ & -39.37 \\
Qitaihe & 4192.208 & 2608.782 & -1583.426 & -37.77 \\
Shuangyashan & $12,987.010$ & 7922.788 & -5064.222 & -39.00 \\
Jixi & $14,263.712$ & 6083.324 & -8180.388 & -57.35 \\
Jiamusi & $14,885.318$ & 3873.499 & $-11,011.819$ & -73.98 \\
Suihua & $16,161.840$ & 4618.782 & $-11,543.058$ & -71.42 \\
Qiqihar & 7695.127 & 906.444 & -6788.683 & -88.22 \\
Daqing & 6412.986 & 341.615 & -6071.371 & -94.67 \\
Total & $287,024.575$ & $180,357.005$ & $-106,667.570$ & -37.16
\end{tabular}




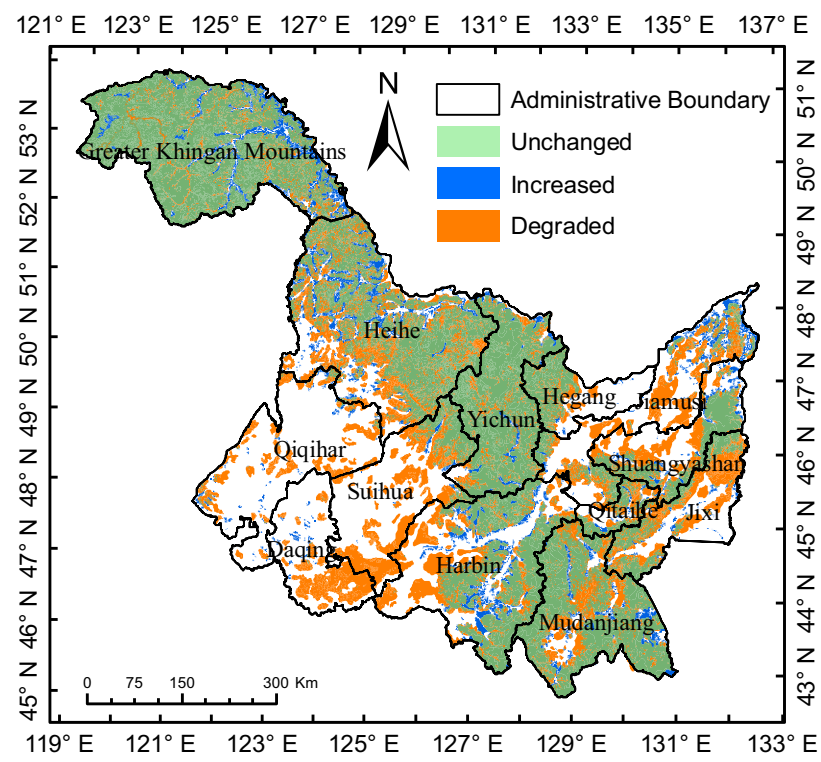

Fig. 3 Spatial variation for the centennial forest of Heilongjiang from 1900 to 2009

production was distributed as expected within the year. Increasing temperatures in March correspond with increased plant photosynthesis and greater oxygen production; both processes peaked in July. Oxygen production then decreased following lower temperatures after the July peak. There were obvious changes in the spatial distributions of the amount of forest oxygen produced annually for both 1900 and 2009. The highest levels of forest oxygen production were in the southwest of Heilongjiang in 1900. However, in 2009, the same area had the lowest levels of forest oxygen production, at essentially zero. Most of the Sanjiang Plain produced forest oxygen in 1900, compared to only east areas of the Sanjiang Plain in 2009. Forest oxygen production also significantly decreased in the central areas of Heilongjiang Province.
With the exception of Yichun, all of the counties and cities in Heilongjiang showed decreased oxygen production in 2009 (Table 4). Oxygen production significantly decreased by more than $90 \%$ in Daqing City and Qiqihar City; more than $50 \%$ in Jiamusi City, Suihua City, and Jixi City; and more than $25 \%$ in Shuangyashan, Qitaihe, Heihe, and Hegang City. A significance test for oxygen was conducted for the years 1900 and 2009 in all cities and yielded a value of 0.000 , indicating that oxygen production was significantly different throughout the 100 -year period. Therefore, it was evident that oxygen production in 2009 was significantly reduced compared with 1900.

\section{Analysis of reasons for the forest oxygen production change in Heilongjiang}

The impact of climate change (including climate warming and increased $\mathrm{CO}_{2}$ concentrations) on forest oxygen production

Over the past century (1900-2009), the average temperature change in Heilongjiang corresponded to the increasing trend in forest photosynthesis (March-November). The linear trend coefficient was $0.134{ }^{\circ} \mathrm{C} / 10 \mathrm{a}$ (see Fig. 5), and the significance probability test value was 0.000 , demonstrating a significant upward trend in the average monthly temperature from the March to November period over 100 years. Indeed, the average annual temperature of Heilongjiang from March to November was $1.24{ }^{\circ} \mathrm{C}$ higher in 2006-2009 than in 1900-1905. There were few changes in radiation over the century (1900-2009) in Heilongjiang. However, significant increases were seen in atmospheric $\mathrm{CO}_{2}$ concentrations. In 2009, the $\mathrm{CO}_{2}$ concentration had increased by $84 \mathrm{ppm}$ compared with 1900 . Three control experiments were conducted as part of this research. In the first, invariance in the forest cover NDVI of 1900 was
Table 3 Simulation results for forest oxygen production of Heilongjiang $\left(10^{7} \mathrm{~kg}\right)$

\begin{tabular}{|c|c|c|c|c|c|c|c|}
\hline Month & Jan & Feb & Mar & Apr & \multicolumn{2}{|c|}{ May } & Jun \\
\hline 1900 estimates & 0 & 0 & 67.622 & 403.793 & \multicolumn{2}{|c|}{2209.667} & 4951.906 \\
\hline 2009 estimates & 0 & 0 & 49.522 & 313.5861 & \multicolumn{2}{|c|}{1917.915} & 3334.077 \\
\hline Control experiment 1 & 0 & 0 & 71.490 & 484.207 & \multicolumn{2}{|c|}{2801.132} & 5954.824 \\
\hline Control experiment 2 & 0 & 0 & 70.661 & 437.536 & \multicolumn{2}{|c|}{2517.261} & 5268.017 \\
\hline Control experiment 3 & 0 & 0 & 66.833 & 422.413 & \multicolumn{2}{|c|}{2441.600} & 5871.619 \\
\hline Month & Jul & Aug & Sep & Oct & Nov & Dec & Yearly \\
\hline 1900 estimates & 5229.030 & 4836.383 & 2739.034 & 475.995 & 58.474 & 0 & $20,971.907$ \\
\hline 2009 estimates & 3968.617 & 3615.644 & 1846.385 & 269.542 & 35.054 & 0 & $15,350.343$ \\
\hline Control experiment 1 & 6948.197 & 6039.552 & 3005.160 & 590.528 & 57.317 & 0 & $25,952.407$ \\
\hline Control experiment 2 & 5264.704 & 4991.595 & 2781.467 & 554.376 & 56.848 & 0 & $21,942.465$ \\
\hline Control experiment 3 & 6333.483 & 5805.046 & 3113.375 & 495.912 & 57.557 & 0 & $24,607.838$ \\
\hline
\end{tabular}



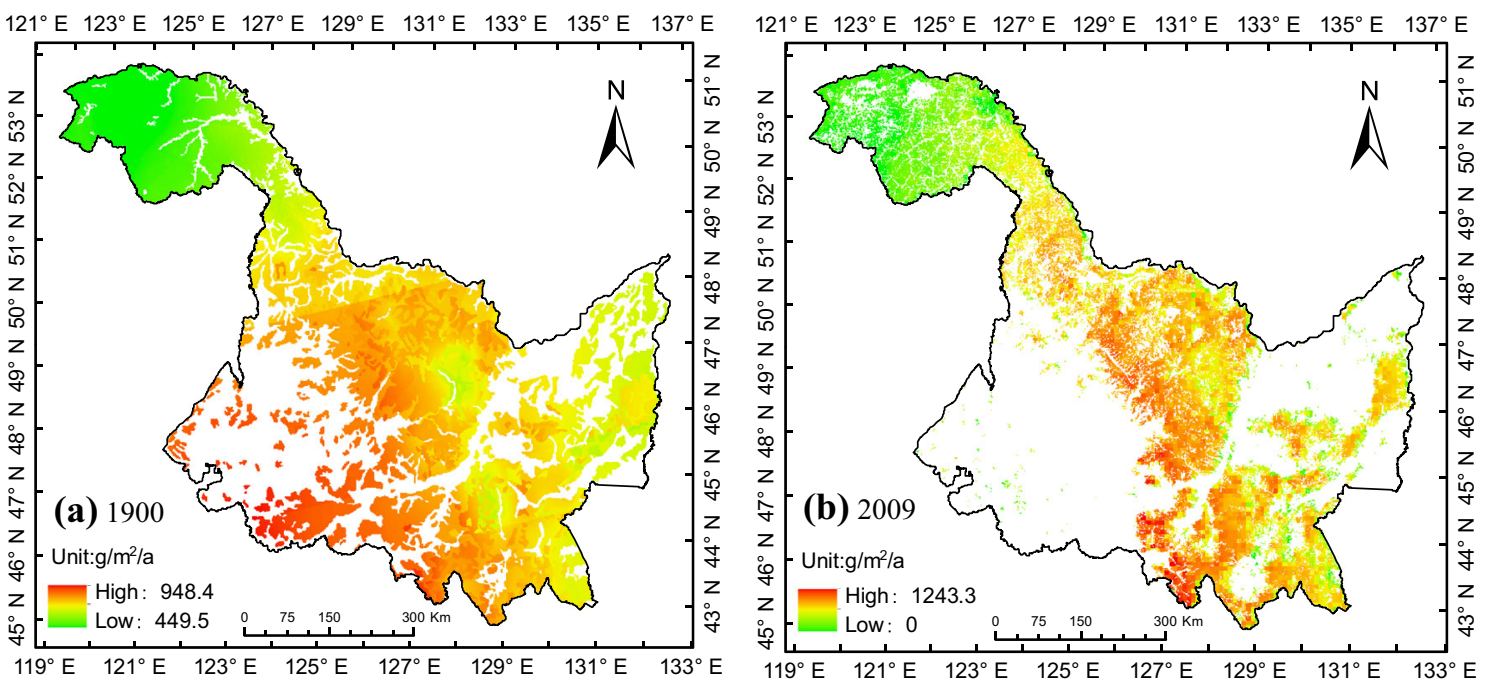

Fig. 4 Spatial distribution for annual amounts of forest oxygen production for Heilongjiang in 1900 and 2009

Table 4 Oxygen production changes in the forest vegetation of Heilongjiang in 1900 and 2009

\begin{tabular}{|c|c|c|c|c|}
\hline District & $1900\left(\times 10^{7} \mathrm{~kg}\right)$ & $2009\left(\times 10^{7} \mathrm{~kg}\right)$ & $\begin{array}{l}\text { Oxygen production } \\
\text { changes }\left(\times 10^{7} \mathrm{~kg}\right)\end{array}$ & $\begin{array}{l}\text { Rate of oxygen production } \\
\text { change }(\%)\end{array}$ \\
\hline Daqing & 582.904 & 20.423 & -562.481 & -96.50 \\
\hline Qiqihar & 664.312 & 72.433 & -591.879 & -89.10 \\
\hline Jiamusi & 1072.91 & 330.655 & -742.255 & -69.18 \\
\hline Suihua & 1386.593 & 482.854 & -903.739 & -65.18 \\
\hline Jixi & 1030.339 & 510.848 & -519.491 & -50.42 \\
\hline Shuangyashan & 921.746 & 680.901 & -240.845 & -26.13 \\
\hline Qitaihe & 310.171 & 229.262 & -80.909 & -26.09 \\
\hline Heihe & 3829.228 & 2833.676 & -995.552 & -26.00 \\
\hline Hegang & 578.123 & 441.986 & -136.137 & -23.55 \\
\hline Harbin & 2701.851 & 2255.278 & -446.573 & -16.53 \\
\hline Greater Khingan Mountains & 3037.534 & 2754.864 & -282.670 & -9.31 \\
\hline Mudanjiang & 2544.448 & 2385.527 & -158.921 & -6.25 \\
\hline Yichun & 2311.748 & 2351.636 & 39.888 & 1.73 \\
\hline Total & $20,971.907$ & $15,350.343$ & -5621.564 & -26.81 \\
\hline
\end{tabular}

maintained, and the simulated value of forest oxygen production was subsequently obtained using the drive model of 2009 temperature, radiation, and $\mathrm{CO}_{2}$ concentration values. The difference between the simulated and actual oxygen produced yielded a value that illustrated that the amount of forest oxygen production was influenced by climate change (increased $\mathrm{CO}_{2}$ concentration and climate warming).

$\Delta \mathrm{O}_{2, \text { climate, } \mathrm{CO}_{2}}=\mathrm{O}_{2, \text { control1 }}-\mathrm{O}_{2,1990}$

where $\Delta \mathrm{O}_{2, \text { climate, } \mathrm{CO}_{2}}$ is the change value of forest oxygen

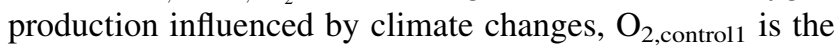
simulation value of forest oxygen production in control experiment 1 , and $\mathrm{O}_{2,1900}$ is the simulation value of forest oxygen production in 1900 .

The results of control experiment 1 are shown in Table 3. The results demonstrated that $\mathrm{O}_{2 \text {,control1 }}$ was 259.524 million tons, $\mathrm{O}_{2,1900}$ was 209.719 million tons, and $\Delta \mathrm{O}_{2 \text {,climate, } \mathrm{CO}_{2}}$ was 49.805 million tons. This was equivalent to a $23.75 \%$ increase when compared with oxygen production in 1900. Evidently, the amount of forest oxygen produced has increased by about $25 \%$ due to climate changes (see Fig. 6a). Meanwhile, the spatial distribution showed significant increases in oxygen production in the southwest. This suggests that forest oxygen production is highly sensitive to changes in natural conditions. 
Fig. 5 Average temperature trend changes of Heilongjiang Province between March and November from 1900 to 2009

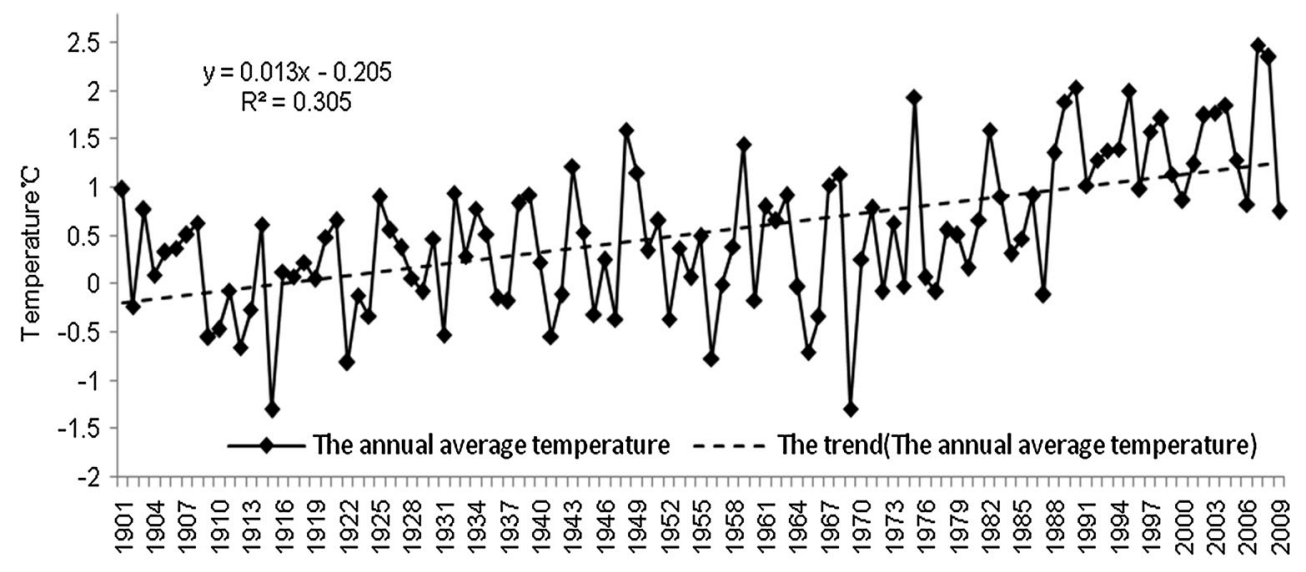

Year
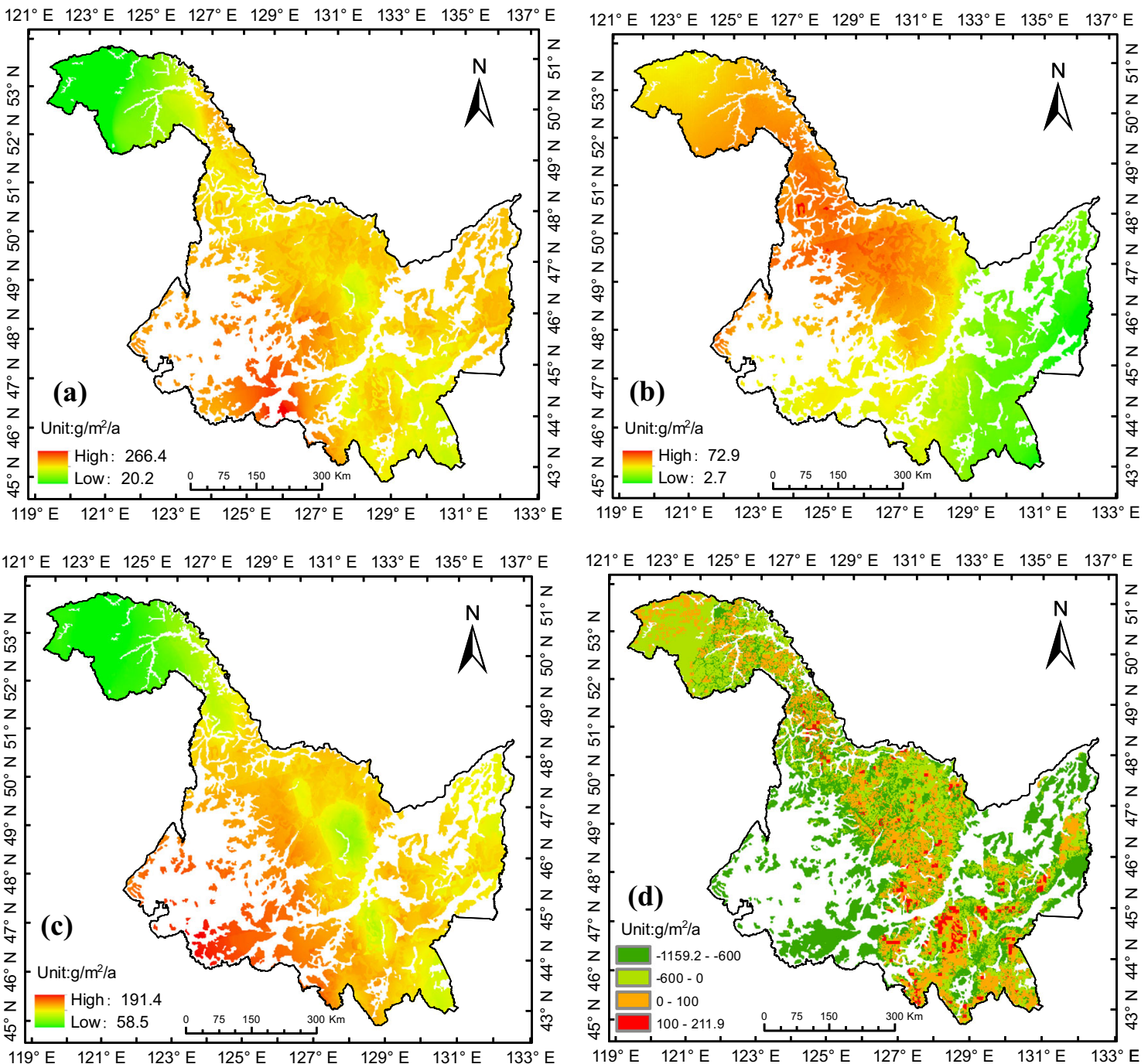

Fig. 6 Effect of climatic change (a), climatic warming (b), $\mathrm{CO}_{2}$ density change (c), forest changes (d) on forest oxygen production 
Simulation of the impact of climate warming on forest oxygen production

By maintaining the invariance of the forest cover properties and $\mathrm{CO}_{2}$ concentration in Heilongjiang Province during the past century, the simulated value of forest oxygen production could be obtained using the drive model of NDVI in 1900, $\mathrm{CO}_{2}$ concentration and radiation in 1900, and temperature in 2009. The difference between the simulated value and the actual oxygen produced provided the value of forest oxygen production influenced by climate change (climate warming).

$\Delta \mathrm{O}_{2, \text { climate }}=\mathrm{O}_{2, \text { control2 }}-\mathrm{O}_{2,1990}$

where $\Delta \mathrm{O}_{2, \text { climate }}$ is the change value of forest oxygen production influenced by climate warming, $\mathrm{O}_{2 \text {,control2 }}$ is the simulation value of forest oxygen production in control experiment 2, and $\mathrm{O}_{2,1900}$ is the simulation value of forest oxygen production in 1900.

The results of control experiment 2 are shown in Table 3. Quantity changes in the spatial distribution of forest oxygen (Fig. 6b) under the conditions of control experiment 2 were obtained by the superposition of forest oxygen production in 1900 . The results of control ex-

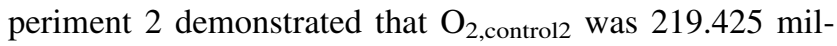
lion tons, $\mathrm{O}_{2,1900}$ was 209.719 million tons, and $\Delta \mathrm{O}_{2 \text {,climate }}$ was 9.706 million tons. This is equivalent to a $4.63 \%$ increase in oxygen production compared with 1900, which is attributable to climate warming. As shown in Fig. 6b, oxygen production markedly increased due to climate warming, while the spatial distribution demonstrated a significant increase in oxygen production in the central area of the province. This suggests that forest oxygen production in the central region is highly sensitive to the influence of climate warming.

\section{Simulation of the impact of $\mathrm{CO}_{2}$ concentration increases on forest oxygen production}

By maintaining the invariance of the forest cover properties and climate changes in Heilongjiang during the past century, control experiment 3 was performed to obtain the simulated value of the forest oxygen production with the use of the drive model of NDVI, climate conditions of 1900 , and $\mathrm{CO}_{2}$ concentration of 2009. The difference between the simulation value and actual oxygen production was pinpointed as the value of forest oxygen production influenced by increases in $\mathrm{CO}_{2}$ concentration.

$\Delta \mathrm{O}_{2, \mathrm{CO}_{2}}=\mathrm{O}_{2, \text { control3 }}-\mathrm{O}_{2,1990}$

where $\Delta \mathrm{O}_{2, \mathrm{CO}_{2}}$ is oxygen production change influenced by increased $\mathrm{CO}_{2}$ density, $\mathrm{O}_{2 \text {, control3 }}$ is the simulation value in control experiment 3 , and $\mathrm{O}_{2,1900}$ is the simulation value of forest oxygen production in 1900.

The results of control experiment 3 are shown in Table 3. The superposition of forest oxygen production in 1900 was used to identify the increasing quantity of forest oxygen under the conditions of control experiment 3 . The results demonstrated that $\mathrm{O}_{2 \text {,control3 }}$ was 246.078 million tons, $\mathrm{O}_{2,1900}$ was 209.719 million tons, and $\Delta \mathrm{O}_{2, \mathrm{CO}_{2}}$ was 36.359 million tons. This is equivalent to a $17.34 \%$ increase in oxygen production compared with 1900 due to higher $\mathrm{CO}_{2}$ concentration. As illustrated in Fig. 6c, the oxygen production of the entire province increased due to higher $\mathrm{CO}_{2}$ concentration. Meanwhile, the spatial distribution showed the most significant increases in forest oxygen production in southwest Heilongjiang Province, indicating that this area is more sensitive to increased $\mathrm{CO}_{2}$ levels.

Simulation of the impact of changes in the forest properties on forest oxygen production

The difference between the results of control experiment 1 and the simulated value of actual forest oxygen production in 2009 indicates that the simulated value of forest oxygen production was influenced by forest property changes.

$\Delta \mathrm{O}_{2, \text { forest }}=\mathrm{O}_{2,2009}-\mathrm{O}_{2, \text { control1 }}$

where $\Delta \mathrm{O}_{2 \text {,forest }}$ is the change value of oxygen production influenced by the forest property change, $\mathrm{O}_{2, \text { controll }}$ is the simulation value in control experiment 1 , and $\mathrm{O}_{2,2009}$ is the simulation value of forest oxygen production in 2009 .

The results of control experiment 1 demonstrate that $\mathrm{O}_{2, \text { control1 }}$ was 259.524 million tons, $\mathrm{O}_{2,2009}$ was 153.503 million tons, and $\Delta \mathrm{O}_{2 \text {,forest }}$ was -106.021 million tons. This was equivalent to a decrease of $50.55 \%$ in oxygen production compared with 1900 due to forest changes. The results of control experiment 1 and the oxygen production map of 2009 were super-positioned to obtain a space variation map of forest oxygen production that indicated the influence of forest changes (Fig. 6d). Forest oxygen production decreased by $202,622 \mathrm{~km}^{2}$ in some areas, but it also increased by $80,993 \mathrm{~km}^{2}$ in others due to forest changes by spatial statistics. The area that caused decreases in oxygen production was 2.5 times more influential than the area causing increased oxygen production. The latter was located in the central region of the province and showed a zonal distribution from south to north. As there were no human activities in this area, oxygen production increased, and the forest became thicker as a result of climate change. However, forest area decreased in the areas influenced by human activities, resulting in an overall decrease in oxygen production, even though the climate conditions were beneficial for vegetation growth. 
Comparative analysis of the impact of natural and human activities on forest oxygen production

Firstly, based on the above results, a comparison of different influences on forest oxygen production, including changes in forest properties, climate warming, and $\mathrm{CO}_{2}$ concentration increases, is shown in Fig. 7. Two conclusions could be concluded from this comparison. Changes in natural factors, such as climate changes, climate warming, and $\mathrm{CO}_{2}$ density changes, are likely to cause an increase in forest oxygen production, while forest changes are likely to decrease oxygen production. When considering the total variation of oxygen production as $100 \%$, forest change accounted for $67.95 \%$, compared to $32.05 \%$ for natural factors. More precisely, forest change could be considered as the key factor in decreased forest oxygen production in Heilongjiang. In addition, among the natural factors, climate warming accounted for $23.30 \%$ and increases in $\mathrm{CO}_{2}$ concentration accounted for $77.70 \%$, indicating that increases in $\mathrm{CO}_{2}$ concentration were more influential than climate warming. Lastly, there were increases in temperature and in $\mathrm{CO}_{2}$ concentration, but minimal increase in radiation over the 100-year period in Heilongjiang, which proved highly beneficial for photosynthesis. However, oxygen production decreased over this period, further indicating that a decrease in the forest area was the significant driving factor for reductions in regional oxygen production.

Secondly, the average temperature difference between 1900 and 1905 in Heilongjiang was $0.3{ }^{\circ} \mathrm{C}$, increasing to $1.54{ }^{\circ} \mathrm{C}$ between 2006 and 2009. This was an overall average temperature increase of $1.24{ }^{\circ} \mathrm{C}$. The annual precipitation in Heilongjiang was $405.8 \mathrm{~mm}$ in 1900 and $486.8 \mathrm{~mm}$ in 2009 . This was an annual precipitation increase of $81.0 \mathrm{~mm}$. The $\mathrm{CO}_{2}$ concentration in the atmosphere also increased by $84 \mathrm{ppm}$. These natural conditions were conducive for lush forest growth and should have

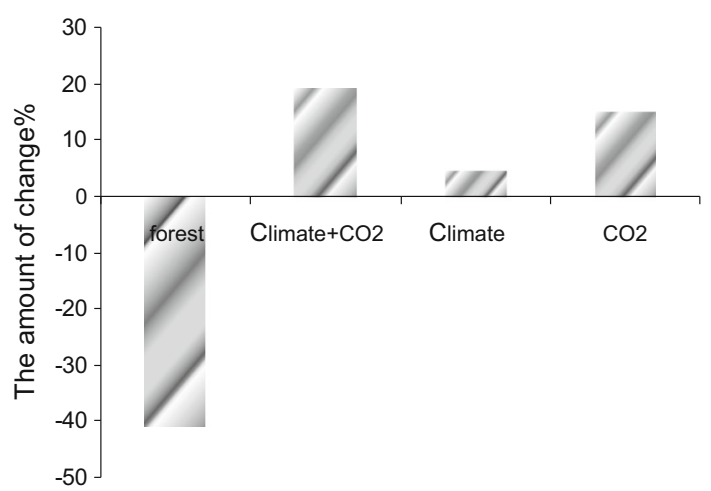

Fig. 7 Comparison between the impact of forest change and climate change on forest oxygen production increased forest oxygen production. However, due to changes in forest properties and area over the 100-year period, oxygen production dropped by nearly a third. This can be attributed in large part to artificial activities that led to decreases in the forest area. If adverse climate conditions had also occurred, in turn affecting forest growth, there would have been an even more significant decrease in forest oxygen production.

\section{Simulating the results test for forest oxygen production and NEP}

Most other studies employed the carbon-oxygen balance approach for estimating forest annual oxygen production for different areas. Zhang et al. (2007) estimated the annual forest oxygen production for Zhengzhou, China as $24.0 \mathrm{t} /$ $\mathrm{hm}^{2}$ in 2010; Peng (2003), and Guang et al. (1998) estimated these values for Guangzhou and Pearl River Delta as 12.70 and $10.59 \mathrm{t} / \mathrm{hm}^{2}$, respectively, based on NPP; Su et al. (2010) calculated the annual forest oxygen production for broad-leaved and coniferous forests in Nanjing as 12.52 and $13.51 \mathrm{t} / \mathrm{hm}^{2}$, respectively, using NPP. In addition, Deng and Gong (2010) examined the forest oxygen production for evergreen broadleaf, deciduous, and boreal forests as $18.53,17.11$, and $11.39 \mathrm{t} / \mathrm{hm}^{2}$, respectively. Nakazawa (1997) concluded that broadleaf forest production is $18.25 \mathrm{t} / \mathrm{hm}^{2}$; Berbigier et al. (2001) estimated the annual forest oxygen production in France as $11.468 \mathrm{t} / \mathrm{hm}^{2}$. In this study, we simulated the annual forest oxygen production for Heilongjiang Province, China as $8.055 \mathrm{t} / \mathrm{hm}^{2}$, with the annual forest oxygen production for different forest types ranging from 6.049 to $8.697 \mathrm{t} / \mathrm{hm}^{2}$. In comparison, although all studies mentioned above assessed different study areas with different estimated quantities of annual forest oxygen production, they are all in the same order of magnitude. Because there is no full consideration of respiration for GPP- and NPP-based approaches for the estimation of annual forest oxygen production, the estimated quantity is quite different from the simulated results in this study. In addition, the other reason could be that different approaches have been used for estimating NPP, including forest volume-based, biomass-based, and literature review-based methods. The simulated results in this study indicate that spruce-fir and Korean pine forests have the highest levels of oxygen production, a result that is consistent with the findings described by Su et al. (2010).

In addition, we also validated the C-FIX model-generated NEP in Heilongjiang Province. In particular, the NPP was calculated using the stock volume-productivity model (Fang et al. 1996) in 37 randomly selected sample regions based on the forest inventory data for Yichun in 2000. Further, the NEP was examined through the heterotrophic respiration northeast model (Zhou et al. 2004), with $\mathrm{gC} / \mathrm{m}^{2} /$ 
a as the final unit. The RMSE is 16.33 , which is about $3.8-5.0 \%$ of the original data, and indicates that the model performed well. The annual average value for NEP in Heilongjiang Province is $316.727 \mathrm{gC} / \mathrm{m}^{2} / \mathrm{a}$. Although the simulated results are slightly lower than the general average forest NEP ( $578 \mathrm{gC} / \mathrm{m}^{2} / \mathrm{a}$, Zhang et al. 2010), it is reasonable because the average temperature for Heilongjiang Province is lower. In this study, we revealed the change of forest oxygen production in Heilongjiang Province in the twentieth century. Therefore, the error generated by the C-FIX model for NEP can be considered as a systematic error that has minimal impact on the change trend of oxygen production.

\section{Conclusion}

Spatial variation in forest oxygen production was relatively obvious in the southwest and the Sanjiang Plain. Falling from its status as the highest oxygen production area, the southwest subsequently became the lowest producing area, at values of almost zero. Due to a reduction in forest area, there have been obvious oxygen production decreases in the Sanjiang Plain. There was also a clear decrease in oxygen production in central Heilongjiang. Over the past 100 years, the overall amount of forest oxygen produced in all regions of Heilongjiang declined, with the exception of Yichun. Notably, forest oxygen production significantly decreased by more than $90 \%$ in Daqing City and Qiqihar City; more than $50 \%$ in Jiamusi City, Suihua City, and Jixi City; and more than $25 \%$ in Shuangyashan City, Qitaihe City, Heihe City, and Hegang City.

Changes in natural factors, such as climate warming and increases in $\mathrm{CO}_{2}$ concentration, have caused subsequent increases in forest oxygen production. However, a significant decrease in forest area due to human activities has contributed to an overall decrease in forest oxygen production. Changes in forest oxygen production were found to be $67.95 \%$ due to changes in forest area and $32.05 \%$ as a result of natural factors. During the increase in forest oxygen production caused by natural factors, $23.30 \%$ was attributed to climate warming, and $77.70 \%$ was attributed to increases in $\mathrm{CO}_{2}$ concentration. Collectively, the data demonstrate that an increase in $\mathrm{CO}_{2}$ concentration was the most influential natural factor in the increase in forest oxygen production.

Further research in this area would be highly beneficial. This study focused on the simulation of regional oxygen production; however, consideration also needs to be given to the large amount of oxygen consumed through human breathing, fuel combustion, and industrial production, among other factors. As the net increase in oxygen was defined using the difference between regional oxygen production and consumption, additional studies are required into the influences of these factors. In addition, air flow introduces a vertical exchange in addition to a horizontal exchange. Therefore, considering atmospheric exchange conditions and converting regional oxygen production into atmospheric oxygen concentration is a very complicated process. A long-term, in-depth study is required to verify this process. Lastly, the absence of long-term observation data of oxygen means that the results estimated in this study would benefit from comparison with other results.

Acknowledgments This study was financially supported by the National Natural Science Foundation of China (No. 41271217) and the key National Natural Science Foundation of China (No. 41030743).

\section{References}

Abbaspour M, Javid AH, Mirbagheri SA, Ahmadi Givi F, Moghimi P (2012) Investigation of lake drying attributed to climate change. Int J Environ Sci Technol 9(2):257-266. doi:10.1007/s13762012-0031-0

Bangian AH, Ataei M, Sayadi A, Gholinejad A (2012) Optimizing post-mining land use for pit area in open-pit mining using fuzzy decision making method. Int $\mathbf{J}$ Environ Sci Technol 9(4):613-628. doi:10.1007/s13762-012-0047-5

Bekker A, Holland HD, Wang PL, Rumble D, Stein HJ, Hannah JL, Coetzee LL, Beukes NJ (2004) Dating the rise of atmospheric oxygen. Nature 427(6970):117-120

Berbigier P, Bonnefond JM, Mellmann P (2001) $\mathrm{CO}_{2}$ and water vapour fluxes for 2 years above Euro flux forest site. Agric For Meteorol 108:183-197

Bortkovskii RS, Egorov BN, Kattsov VM, Pavlova TV (2007) Model estimates for the mean gas exchange between the ocean and the atmosphere under the conditions of the present-day climate and its changes expected in the 21st century. Izv Atmos Ocean Phys 43(3):378-383. doi:10.1134/S0001433807030127

Chen B, Shan L (2009) Valuing ecological services of green space of west lake scenic area in Hangzhou. J Zhejiang Univ Agric Life Sci 35(6):686-690

Chen YH, Li XB, Chen J, Shi PJ (2002) The change of navy time series based on change vector analysis in china, 1983-1992. J Remote Sens 6(1):12-19

Chen HL, Zhou CH, Liu YJ, Xu XD (2005) 1983-1992 Vector analysis on change of China land vegetation NDVI evolution characteristics, China meteorological society annual meeting. pp 3670-3680

Chuai X, Chen X, Yang L, Zeng J, Miao A, Zhao H (2012) Effects of climatic changes and anthropogenic activities on lake eutrophication in different ecoregions. Int J Environ Sci Technol 9(3):503-514. doi:10.1007/s13762-012-0066-2

Claire MW, Catling DC, Zahnle KJ (2006) Biogeochemical modelling of the rise in atmospheric oxygen. Geobiology 4(4):239-269. doi:10.1111/j.1472-4669.2006.00084.x

Deng Y, Gong ZX (2010) Research on the calculate methods of urban ecological park's utility function capability. Sichuan Buliding Sci 36(3):304-307

Fang JY, Liu GH, Xu SL (1996) Biomass and net production of forest vegetation in China. Acta Ecol Sin 16(5):497-508

Fang XQ, Zhang XZ, Dai YJ, Li BB, Hou GL (2010) Regionalization of Winter Temperature Change over Mainland of China During 1951-2005. Sci Geogr Sin 30(4):571-576 
Francis S, Johnson C (1970) The balance of atmospheric oxygen and carbon dioxide. Biol Conserv 2(2):83-89

Goldblatt C, Timothy ML, Watson AJ (2006) Bistability of atmospheric oxygen and the Great Oxidation. Nature 443 (7112):683-686. http://www.nature.com/nature/journal/v443/ n7112/suppinfo/nature05169_S1.html

Guang DS, Chen YJ, Huang FF (1998) The storage and distribution of carbon in urban vegetation and its roles in balance of carbon and oxygen in Guangzhou. Chin Environ Sci 18(5):437-441

Huang ZZ, Pan YQ (2008) A statistics-based method for hourly sun radiation calculation. Paper presented at the Chinese Association of refrigeration on BBS for The 2008 academic annual meeting, Beijing

Jacobsen Dean (2008) Low oxygen pressure as a driving factor for the altitudinal decline in taxon richness of stream macroinvertebrates. Oecologia 154(4):795-807. doi:10.1007/s00442-007$0877-\mathrm{x}$

Johnson FS (1970) The oxygen and carbon dioxide balance in the earth's atmosphere. In: Fred Singer S (ed) Global effects of environmental pollution. Springer, Netherlands, pp 4-11

Kasting JF, Liu SC, Donahue TM (1979) Oxygen levels in the prebiological atmosphere. J Geophys Res Oceans 84(C6):3097-3107. doi:10.1029/JC084iC06p03097

Keeling RF, Stephen RS (1992) Seasonal and interannual variations in atmospheric oxygen and implications for the global carbon cycle. Nature 358(6389):723-727

Keeling RF, Andrew CM, Elizabeth MM, Stephen RS (1998) Methods for measuring changes in atmospheric $\mathrm{O} 2$ concentration and their application in southern hemisphere air. J Geophys Res Atmos 103(D3):3381-3397. doi:10.1029/97JD02537

Kump LR, Mark EB (2007) Increased subaerial volcanism and the rise of atmospheric oxygen 2.5 billion years ago. Nature 448 (7157):1033-1036. http://www.nature.com/nature/journal/v448/ n7157/suppinfo/nature06058_S1.html

Li JW (1993) The forest of Heilongjiang Province. Northeast Forestry University Press, Harbin

Li WL, Wu CS (2013) A spatially explicit method to examine the impact of urbanisation on natural ecosystem service values. J Spatial Sci 58(2):275-289. doi:10.1080/14498596.2013. 797372

Li WL, Wu CS, Zang SY (2012) Modeling urban land use conversion of Daqing City, China: a comparative analysis of "top-down" and "bottom-up" approaches. Stoch Environ Res Risk Assess. doi:10.1007/s00477-012-0671-0

Li L, Wang Y, Liu C (2013) Effects of land use changes on soil erosion in a fast developing area. Int $\mathrm{J}$ Environ Sci Technol. doi:10.1007/s13762-013-0341-x
Lu L (2003) In the western of China, net primary productivity and carbon cycle research. Chin Acad Sci, Beijing

Ma JY, Yin K, Lin T (2011) Analysis of the carbon and oxygen balance of a complex urban ecosystem: a case study in the coastal city of Xiamen. Acta Sci Circum 31(8):1808-1816

Manning AC, Keeling RF, Katz LE, Paplawsky WJ, McEvoy EM (2003) Interpreting the seasonal cycles of atmospheric oxygen and carbon dioxide concentrations at American Samoa Observatory. Geophys Res Lett 30(6):1328-1333

Melemez K (2013) An environmental assessment of forest stands damages caused by excavators during road construction in Beech forests. Int J Environ Sci Technol 10(4):645-650. doi:10.1007/ s13762-012-0125-8

Nakazawa T (1997) Variation and cycles of carbon dioxide and methence. Global Environ Res 2:5-14

Peng JY (2003) Roles of vegetation on balance of carbon and oxygen in the Pearl River Delta. Acta Sci Nat Univ Sunyatseni 42(5):105-108

Sreenivas B, Murakami T (2005) Emerging views on the evolution of atmospheric oxygen during the Precambrian. J Mineral Petrol Sci 100(5):184-201. doi:10.2465/jmps.100.184

Su JS, ZHuang JY, Gu Y, Min JJ (2010) Benefit assessment of carbon fixation and manfacturing oxygen of urban forests in Nanjing city. For Sci Technol 24(3):49-52

Yan K (2009) Research on tendency equation about the concentration data of carbon dioxide in the atmosphere over the past 60 years. Prog Geophys 24(5):1665-1670

Zhang DY (2009) Estimation of forest net primary productivity in Heilongjiang province based on remote sensing. Beijing Forest University, Beijing

Zhang CJ, Li DL, Wang XP (2004) Study on precipitation variability in last 100 years and trend prediction in Northeast Asia in future 10-15 years. Plateau Meteorol 23(6):919-928

Zhang Y, Wang QL, Li BJ, Wang WM (2007) Study on forecasting ecological land demand with carbon-oxygen balance method. China Land Sci 21(6):23-28

Zhang J, Yuan WG, Ge Y, Jiang B, Zhu JR, Shen AH, Chang J (2010) Carbon storage and its sequestration potential by ecological service forest in Zhejiang. Acta Ecol Sin 30(14):3839-3848

Zhou HF (1999) Discussion in synthetic index of climatic change influence on human health. Clim Environ Res 4(1):121-126

Zhou SZ (2003) Meteorology and climatology. Higher Education Press, Beijing

Zhou T, Shi PJ, Sun R, Wang SQ (2004) The impacts of climate change on net ecosystem production in China. Acta Geograph Sin 59(3):357-365 